\title{
Análise descritiva da tradução de Millôr Fernandes para o português da peça Pygmalion, de George Bernard Shaw
}

Priscila Fernanda Furlanetto

\section{Introdução}

As obras de um dos mais conhecidos humoristas brasileiros, Millôr Fernandes, já foram bastante exploradas pelos pesquisadores de uma forma geral. Mesmo assim, há ainda uma vertente desse autor a ser estudada: o Millôr Tradutor.

O nosso maior objetivo neste trabalho é analisar a tradução da obra Pygmalion, escrita por George Bernard Shaw em 1913, e traduzida para o português pelo autor-tradutor Millôr Fernandes em 1963. Em cinco atos, a peça trata do professor de fonética Henry Higgins, que se prontifica a transformar Eliza Doolittle, uma vendedora de flores que fala o dialeto cockney, em uma verdadeira dama, ensinando-a a falar corretamente.

O que nos chama a atenção nesta obra de Shaw é o dialeto cockney e as muitas expressões que encontramos no decorrer da peça. A nossa grande intenção é, portanto, mostrar as dificuldades e soluções encontradas por Millôr ao traduzir Pygmalion.

Como estamos lidando com uma peça teatral e sua tradução, não podemos deixar de falar sobre a tradução de teatro, mostrando 
Priscila Fernanda Furlanetto. Análise descritiva da tradução de Millôr Fernandes...

ao leitor quais são as maiores dificuldades que um tradutor encontra ao trabalhar gênero tão complexo.

\section{A tradução de teatro}

Uma das atividades mais difíceis que o homem é capaz de exercer é a tradução. Segundo Rosemary Arrojo (1999, p. 10) a tradução "implica necessariamente uma definição dos limites e do poder dessa capacidade tão humana que é a produção de significados".

Traduzir é confrontar duas línguas e, conseqüentemente, duas culturas, possibilitando aos leitores um contato maior com o mundo. Ortega, em seu ensaio "Miséria y Esplendor de la Traducción", diz que a tradução "é uma tarefa misteriosa e impossível, pela qual se pode tentar levar outras línguas e grandes autores a afetar o pensamento e a linguagem de alguém, e assim erguer-se acima do nivelamento cultural da sociedade moderna" (apud Milton, 2002, p. 83).

Ser tradutor, definitivamente, não é uma tarefa fácil: requer sensibilidade artística, vasto conhecimento lingüístico e cultural, além de muita vontade e determinação para chegar a um bom resultado que contribua para a humanidade.

Traduzir é ir além das palavras escritas. O tradutor deve ter consciência de que, ao traduzir uma obra literária, ele deve primeiramente compreendê-la e interpretá-la para que possa passar a outra língua e cultura o que o autor da obra original disse com sua arte.

Cultura e língua são coisas indissociáveis. Jamais seremos capazes de transpor algo de uma língua para outra se não levarmos em consideração a maneira como os falantes de ambas as línguas vivem em seus respectivos países.

Muitas vezes os tradutores são obrigados a fazer mudanças nos textos para que certa expressão ou termo possa ter, na línguaalvo, o mesmo significado ou efeito da língua de origem. Cada povo 
tem sua ideologia, suas crenças, enfim, seu modo de viver, que acaba influenciando muito no seu entendimento de mundo.

Em nosso trabalho fica evidente o quanto língua e cultura estão intimamente ligadas: podemos notar como Millôr trabalhou com a questão da transposição cultural e podemos principalmente estudar um pouco mais esta questão, que é tão intrigante e atraente.

Não podemos perder de vista que quando um tradutor se propõe a traduzir uma obra literária, ele de certa forma é responsável por aquele texto na língua traduzida e muitas vezes se vê desempenhando dois papéis: tradutor e autor. Isso fica claramente perceptível na tradução de Millôr, como veremos logo mais.

No texto "Ways Through the Labyrinth: Strategies and Methods for Translating Theatre Texts", Susan Bassnett nos dá um panorama geral sobre tradução de teatro. Segundo ela, a tradução de teatro encontra problemas como qualquer outra, mas a principal dificuldade está no texto em si. Temos fatores que vão além do lingüístico. $\mathrm{O}$ texto teatral está sempre relacionado com a performance; ambos são inseparáveis. Este é, enfim, o ponto de maior dificuldade: traduzir algo que ao mesmo tempo é escrito e encenado.

Susan Bassnet diz que o maior obstáculo nos estudos do teatro tem sido a contínua ênfase no texto verbal excluindo os outros sistemas de signos envolvidos na criação do teatro. Há muitas discussões sobre o texto escrito e o texto encenado, pois cada qual tem características próprias. $\mathrm{O}$ problema que o tradutor de teatro encara é justamente que se o texto encenado é oculto ou existe positivamente no texto escrito, ele carrega a responsabilidade de transferir não apenas o lingüístico, mas uma série de outros códigos também.

O que percebemos nas traduções de teatro é que cada tradutor acaba escrevendo o seu próprio texto. Assim, na língua-alvo, temos tanto uma tradução do original quanto uma obra única, pois cada tradutor vai escrever sobre os problemas de seu país e dar ênfase ao que acha importante. 
Priscila Fernanda Furlanetto. Análise descritiva da tradução de Millôr Fernandes...

Bassnett diz em Translation Studies que não há como existir entre duas línguas a exata maneira de se dizer a mesma coisa; o que é possível é aproximá-las na questão de perdas e ganhos no processo de tradução.

Este é um ponto da tradução que merecia ser mais discutido: o que se perde na transferência de um texto original para um texto traduzido e o que também pode se ganhar, pois há momentos em que o tradutor pode enriquecer ou melhorar o texto original. Além disso, o que geralmente é visto como perda no contexto do texto original pode ser substituído no contexto do texto traduzido e se transformar em ganho. (BASSNETT, p. 30, 1980)

Segundo Bassnett (1980), um texto dramático não pode ser traduzido como prosa. Para começar, um texto teatral é lido diferentemente, é lido como algo incompleto, como algo que só chega à totalidade quando encenado.

Tendo o texto teatral duas vertentes, a escrita e a encenada, o tradutor acaba caindo em uma questão complicada, indeciso sobre que caminho seguir, uma vez que o teatro só será teatro se texto e performance estiverem juntos.

Ainda de acordo com Bassnett (1980), a tradução de teatro é uma atividade que envolve muitos códigos que giram em torno do texto escrito. Às vezes, o caminho à frente pode estar bem próximo do texto original, enquanto outras vezes deve haver um processo de tradução (intersemiótica), quando a função do texto original é substituída pelo texto da língua-alvo. Não existe certo ou errado, o tradutor deve ter em mente se está conseguindo ou não passar a idéia do texto original para a língua-alvo.

O que é mais complicado é a questão de performability, a qualidade implícita, indefinida do texto teatral que muitos tradutores tentam justificar com suas várias estratégias lingüísticas. Bassnett conclui que apenas por meio da escrita a encenação de qualquer texto teatral é possível. Segundo Anne Ubersfeld, o texto escrito é troué, isto é, não é completo por si só, é o material cru no qual o tradutor tem de 
trabalhar; e é com o texto escrito, mais do que com a hipotética performance, que o tradutor deve começar (apud. BASSNETT, p. 1985).

Em meio a tanta polêmica que envolve a tradução de teatro, é com o texto teatral escrito da obra Pygmalion de George Bernard Shaw, traduzido para o português por Millôr Fernandes, que vamos trabalhar aqui.

\section{Análise da tradução para o português da obra Pygmalion por Millôr Fernandes}

Examinando a tradução, analisaremos como Millôr Fernandes resolveu o problema do dialeto e das expressões que encontramos na peça, uma vez que tais questões não são encontradas com facilidade em livros teóricos. Antes de entrarmos na análise da tradução em si, devemos saber um pouco sobre o tradutor em questão, Millôr Fernandes.

Tendo em vista que Millôr é um autor ligado ao humorismo e que suas obras têm caráter descontraído, despretensioso e até "autogozador" (PAulillo, 1980, p.15) devemos ter em mente que ele sabe usar o idioma de forma brilhante, já que fazer rir não é fácil e é preciso "recorrer a um variado arsenal de recursos estilísticos para provocar e manter o impacto que leva o leitor a rir e, no caso de Millôr, a pensar e pensar-se (PAUlillo, 1980, p. 16).

Podemos presumir que ao traduzir a obra Pygmalion, de Bernard Shaw, Millôr fez uso de toda sua habilidade humorística, de todo seu dom de fazer rir, juntando a estes sua habilidade lingüística para realizar a tradução da melhor maneira possível e conseguir passar a essência da obra original, também uma comédia. Podemos dizer que certamente a tradução reproduz realmente o estilo de Millôr, cuja arte se faz pelo uso "hiperbólico, isto é, exageradíssimo de certos traços fundamentais da linguagem em questão" (Paulillo, 1980, p. 17). 
Priscila Fernanda Furlanetto. Análise descritiva da tradução de Millôr Fernandes...

Em busca de traduções para o português da peça Pygmalion, descobrimos que, além da tradução que já tínhamos em mãos, de Miroel Silveira, havia apenas mais uma brasileira, feita por Millôr Fernandes em 1963 e que teria sido publicada pela Editora Brasiliense, informação encontrada no site do próprio Millôr. Depois de muito procurar, resolvemos ir direto à fonte. Por meio da internet entramos em contato com Millôr, e então descobrimos que seria impossível encontrar a tradução, já que esta não havia sido publicada.

Começaram então, tempos de muito trabalho; nós nos correspondíamos quase todos os dias com Millôr que, com seu jeito irônico, sempre acabava deixando dúvidas se iria, ou não, nos mandar uma cópia de sua tradução para que pudéssemos estudá-la. Ficamos nos comunicando durante mais ou menos seis meses, quando, depois de muito insistir, finalmente o carteiro apareceu com um envelope que continha uma cópia da tradução, revisada a mão pelo próprio autor-tradutor!

Pouco sabemos sobre a história da tradução de Pygmalion por Millôr Fernandes. Logo que começamos a nos corresponder ele nos disse que a obra não havia sido publicada, embora ele a tivesse traduzido em 1963.

Acreditamos que a obra tenha sido traduzida por Millôr com a intenção de ser encenada, pois ele usou a versão de Pygmalion para o cinema - que é uma versão muito mais completa, com longas explicações das cenas, e que foi elaborada exatamente para encenação. Essa versão de que estamos falando é da Pengüim Books de 1957 e nos aparece como definitive text, ou seja, texto definitivo.

Em seus e-mails, Millôr muitas vezes citava como o ator deveria fazer frente ao seu texto traduzido; com intuito de traduzir o dialeto cockney, Millôr diz ter inventado uma linguagem que não é falada em lugar nenhum do Brasil. Em um de seus e-mails o tradutor comentou sobre isso:

(...) Realmente, você ia se interessar pela minha tradução porque, para dar idéia do Shaw, tive que inventar um coquinei em portu- 
guês. Traduzir colocando em caipira, como fez um herói paulista, é apenas ridículo. Não entendeu nada. Fez gracinha. Coisa que um humorista nunca faz. A peça é sobre a impossibilidade de uma pessoa ascender socialmente por falar uma língua paralela, adicional, ou lá como se chame (...).

Como pudemos perceber nas falas do próprio Millôr, ele, inventando um "coquinei", tinha a intenção de ver sua peça em palcos brasileiros. Infelizmente, não podemos confirmar se esta foi encenada na época, ou não. Nossa investigação ainda está em curso; porém, até o momento, não encontramos nada. Presumimos que a peça traduzida por Millôr tenha ficado apenas no papel e é com a peça escrita que trabalharemos aqui.

Sabemos que a tradução de teatro tem uma grande responsabilidade político-social, pois passa para o público a ideologia do autor e, muitas vezes, do próprio tradutor, que faz uso de uma obra para mostrar algo que quer expressar em sua própria cultura.

Lendo a tradução de Millôr, percebemos que sua maior preocupação foi a de não alterar a ideologia da obra original. $\mathrm{O}$ tradutor acaba deixando isso muito claro logo nas páginas 3 e 4 de sua tradução, quando aproveita uma brecha que Shaw faz na obra original para explicar a obra em si e suas idéias sobre ela.

A princípio, na obra original, Shaw tentou transcrever a fala da florista Eliza. Tentava com isso mostrar como era o som do dialeto cockney; logo, porém, ele desiste por ser algo bastante trabalhoso e um tanto impreciso. Ao explicar esta situação, Millôr diz:

(...) A peça Pigmaleão é basicamente o problema da marginalização de pessoas que, dentro de uma comunidade, falariam outra língua - isto é, uma língua tida por ignorante, rude - o que lhes impede o acesso social. O tradutor avisa que é impossível, claro, traduzir cockney para o português. Por outro lado não há a possibilidade de adaptação da peça pelo fato de que, no Brasil, não 
Priscila Fernanda Furlanetto. Análise descritiva da tradução de Millôr Fernandes...

existe nenhum problema lingüístico que se aproxime do criado por uma linguagem dialetal. Assim, o tradutor tentará criar uma língua que, não sendo de parte alguma, possa sugerir a idéia do cockney, uma forma de baixeza lingüística que faz com que representantes da elite repilam ligações mais íntimas (ligações sociais simples, quanto mais casamento!) com pessoas tão ignorantes. (Fernandes, P. 3 e 4, 1963).

No livro A Arte de Traduzir, Brenno Silveira (2004, p. 25) fala um pouco sobre a tradução de dialetos; sobre o tradutor que exerce esta função ele diz: "As melhores traduções são feitas, quase sempre, por tradutores que conhecem a obra, o ambiente e a personalidade literária do autor, tal como esta se reflete em seus livros. São feitas por tradutores que conhecem a história, a literatura e as tendências literárias, sociais, econômicas e filosóficas da época e do país em que viveu o autor".

Pelo que vimos até aqui sobre nosso tradutor e sobre suas idéias quanto à tradução de Pygmalion, podemos dizer que Millôr tem plena consciência da obra e que tentou traduzi-la da melhor maneira possível.

Muitas vezes, ao ler as partes mais cômicas da peça original e da tradução, chegamos a pensar que, em português, a obra acabou ficando mais engraçada e com muito mais humor do que a original.

Se pensarmos que a tradução está diretamente ligada à cultura de cada país, podemos concluir que de fato Millôr usou a nossa cultura e o que consideramos engraçado para traduzir a peça e igualála à original. O humor é relativo e está intimamente ligado à cultura e aos costumes de cada país. Veremos a seguir alguns dos pontos mais relevantes da tradução feita por Millôr, examinando o humor da obra original e o humor da tradução:

Liza: Y-e-e-e-es, Lord love you! Why should she die of influenza? She come through diphtheria right enough the year before. I saw 
her with my own eyes. Fairly blue with it, she was. They all thought she was dead; but my father he kept lading gin down her throat til she came to so sudden that she bit the bowl off the spoon. P. 76

Liza: - Siim seeenhora! Como é que ela ia morrer de gripe? Uma velha forte daquele jeito? Um ano antes ela tinha tido uma difteria daquelas e saiu novinha como se não fosse nada. Vi com estes olhos. Chegou a ficar azul assim, oh! (Pega qualquer fazenda e mostra um azul berrante) Todo mundo pensou que estava morta; mas meu pai não desistiu, continuou enfiando gin pela goela dela abaixo e de repente a velha reviveu com tal força que mordeu a concha da colher. P. 62

Com esse exemplo fica evidente a capacidade do tradutor de manter e talvez até melhorar a comicidade da peça. Vemos que entre parênteses Millôr coloca como Eliza mostraria para o público a cor que sua tia ficara quando doente. Certamente esse acréscimo faz com que o leitor imagine a peça sendo encenada.

O que nos interessa bastante nesta análise é a maneira como a florista Eliza fala, e como esta fala por sua vez foi traduzida. Como já dissemos anteriormente, Millôr afirma ter inventado um "coquinei" para as falas da florista, embora muitas vezes, ao estudar tais falas, cheguemos a questionar se o linguajar que o autor-tradutor usou na tradução possa mesmo ser considerado "invenção".

“The Flower Girl: “Nah then, Freddy: look wh'y gowing, deah". (p. 15)

"Florista: "Divagá cum a lôça, Frederico. Num inxerga não, homi?" (p. 2)

“The flower Girl: Thres menners f'yer?

Te-oo banches o voylets trod into the mad (...)" (p. 15)

"Florista: Qui inducação, qüi modos, nossa sinhora. Cinco burquês de magnólias artolados na lama (...)" (p. 2). 
Priscila Fernanda Furlanetto. Análise descritiva da tradução de Millôr Fernandes...

“Flower Girl: [protesting]

Who's trying to deceive you?

I called him Freddy or Charlie same as you might yourself if you was talking to a stranger and wished to be pleasant " (p.17)

“Florista: (Protestando) Quim é qüi tá enganano a sinhora? Chamei eli di Frederico ô di Carlinho cumu si farla prum istranho quano si qué sê agradavi." (p. 4 ).

Lançando mão de alguns exemplos, podemos tentar estabelecer algumas regras para o "coquinei" inventado por Millôr. Geralmente, no lugar da letra " $\mathrm{e}$ ", o tradutor colocou a letra "i" e vice-versa.

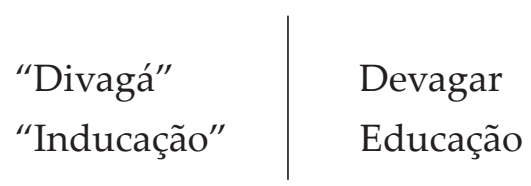

Sem contar que ele omite o " $\mathrm{r}$ " final das palavras e acentua a última vogal, como no "divagá" já citado acima.

Podemos perceber também que, com o intuito de criar um dialeto, Millôr insere letras inexistentes no meio das palavras, colocando " $\mathrm{r}$ " e " $\mathrm{n}$ " onde não é necessário:

$$
\begin{array}{l|l}
\text { "burquês" = buquês } & \text { "farla" = fala } \\
\text { “artolados" = atolados } & \text { "argardavi" = agradável } \\
\text { "inducação" = educação } &
\end{array}
$$

O pronome "que" é sempre tido como "qui" e muitas vezes o autor dá ainda mais ênfase ao som acrescentando tremas e transformando "que" em "qüi". Podemos perceber o mesmo tipo de mudança com o pronome interrogativo: "quem" se transforma em "quim". 
Há também palavras em que algumas letras são omitidas:

$$
\begin{array}{l|l}
\text { "quano" } & \text { quando } \rightarrow \text { temos a omissão do "d" } \\
\text { "enganano" } & \begin{array}{l}
\text { enganando } \rightarrow \text { temos a omissão do "d" } \\
\text { "lôça" }
\end{array} \\
\text { louça } \rightarrow \text { omissão do "u" }
\end{array}
$$

Se analisarmos pacientemente as palavras ditas pela florista Eliza e pelo seu pai, Alfred Doolittle, que também fala o dialeto cockney, notamos que Millôr pensou bastante na construção de seu "coquinei", e que essa construção foi certamente bastante demorada e difícil. Mesmo assim não podemos deixar de notar que nas falas da florista há muito de caipira brasileiro. Ao ler a peça em voz alta ficamos como a impressão de estar escutando um caipira e não conseguimos distinguir o habitual linguajar caipira daquele inventado por Millôr.

Outra coisa que é interessante notar em relação às falas de Eliza é que a partir do Ato III a personagem já não fala mais usando o dialeto cockney. $\mathrm{O}$ argumento da peça permanece o mesmo, porém a discussão é levada para outro lado: a cultura de cada pessoa. Percebemos que, se antes Eliza falava o dialeto cockney e era "marginalizada" por isso, agora ela é marginalizada por não saber conduzir uma conversa, por não ter assuntos apropriados para conversar com pessoas da alta sociedade e por acabar usando expressões que de certa forma são herança do meio em que vivia antes. Isso tudo nos mostra que não adianta "sofisticar" a maneira como as pessoas pronunciam as palavras quando elas não sabem sobre o que falar.

Pelo uso de certos vocábulos desconhecidos da alta sociedade, Shaw faz o humorismo do Ato III. É neste ato que Eliza tem o seu primeiro contato com pessoas da sociedade e é nele ainda que Higgins percebe que, embora a garota já esteja usando um inglês muito melhor do que o de antes, ele ainda tem muito trabalho pela frente.

Alguns exemplos extraídos do Ato III da peça nos mostram o cômico da personagem Eliza mesmo não usando o dialeto cockney: 
Priscila Fernanda Furlanetto. Análise descritiva da tradução de Millôr Fernandes...

"Liza: Not her. Gin was mother's milk to her. Besides, he'd poured so much down his own throat that he knew the good of it." (p. 77)

“Liza: Que o que! Pra ela gin era como leite materno. Sem falar que meu pai, ele mesmo, entornava tanto que conhecia melhor do que ninguém todos os efeitos do álcool." (p. 63)

“Liza: Drank! My word! Something chronic." (p. 77)

"Liza: - Bebia!? Não me deixe rir, minha senhora. Uma esponja!" ( p. 63)

Outra coisa muito importante na obra analisada é a maneira como as expressões são traduzidas. Para uma mesma expressão no inglês, Millôr utiliza diversas traduções no português:

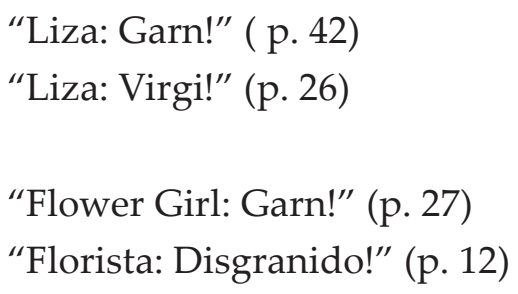

É interessante notar que "garn" é um bordão que caracteriza a personagem Eliza; ao traduzir por "virgi", Millôr acentua tal característica, pelo fato de a garota estar sempre frisando que é uma boa moça e que é honrada. Como "virgi" remete a virgindade, pureza e santidade, o tradutor enriqueceu um bordão que está intimamente ligado a Eliza.

Uma expressão bastante usada pelo personagem "Higgins" é "by George". Millôr traduziu essa expressão de muitas maneiras diferentes: 


\author{
“Higgins : (...) By George, Eliza, (...)" (p. 46) \\ “Higgins: (...) Ah, flôr, nem fala (...)" (p. 26) \\ “Higgins: [turning hopefully] Yes, by George! (...)" (p. 72) \\ "Higgins: (Pegando a bola no ar). Claro, não se incomodem! \\ $(\ldots)^{\prime \prime}$ p. 59
}

"Higgins: [suddenly] By George, yes: it all comes back to me!" (p. 75)

"Higgins: (Subitamente) Com mil diabos, é isso; já me lembro." (p. 61)

“Higgins: (...) By George: (...)" (p. 82)
"Higgins: (...) O diabo que me carregue - (...)" (p. 69)

“Higgins: (...) By George, Pick, (...)" (p. 113)

“Higgins: (...) - Pelas chagas do demônio, Pick, (...)” (p. 92)

"Higgins: (...) Is she, by George? Ho! (...)" (p. 119)

“Higgins: (...) Não diz?!? Está mesmo? A cretina! (...)” (p. 98)

“Higgins: (...) Forgive! Will she, by George! (...)” (p. 120)

"Higgins: (...) Perdoar!?! Que é que você está dizendo,

Pickering!? Com mil demônios,. (...)" (p. 103)

O que podemos notar nas traduções da expressão "by George" é que Millôr não adota um critério rígido para traduzi-la. Na maioria das vezes o tradutor insere a figura do "demônio" ao usar expressões que no português são relativamente fortes e que de certa forma acabam caracterizando o personagem Higgins na obra em português. 
Priscila Fernanda Furlanetto. Análise descritiva da tradução de Millôr Fernandes...

Pela maneira como Higgins se expressa, depreendemos que ele é um personagem explosivo. Com suas opções tradutórias Millôr consegue passar essa forte característica do personagem para a obra traduzida.

Em se tratando de expressões, uma das coisas mais interessantes é o palavrão "bloody" insinuado no início da peça por Mrs. Pearce. "Bloody" era um palavrão bastante forte na época em que Pygmalion foi escrita. Sua tradução acaba sendo complicada pelo fato de a palavra em si, a princípio, não ser mencionada por inteiro: sabemos apenas que sua inicial é" B". George Bernard Shaw faz uma brincadeira com a letra " $B$ " para efeitos de comicidade. Ao traduzir essa passagem, Millôr parece não entender a intenção de Shaw:

"Mrs. Pearce: (...) but there is a certain word I must ask you not use. The girl used it herself when she began to enjoy the bath. It begins with the same letter as bath (...)." (p. 51)

“Sra, Pearce: (...) Mas há uma palavra que eu the peço não repetir. A moça acabou de usá-la ao entrar no banho. Começa com p. (...)" (p. 36)

"Mrs. Pearce: Only this morning, sir, you applied it to your boots, to the butter, and to the brown bread" (p. 51).

"Sra. Pearce: Só esta manhã, professor, o senhor aplicou essa palavra às suas botas, à manteiga e ao pão-de-forma."(p. 37)

"Higgins: Oh, that! Mere alliteration, Mrs. Pearce, natural to a poet" (p. 51)

"Higgins: Ah, ora! Isso não vale. Simples aliteração, madame Pearce - uma licença poética." (p. 37) 
Como pudemos observar, há uma perda significativa de sentido e de comicidade na tradução de Millôr: Mrs. Pearce cita quatro palavras com " $b$ " e o tal palavrão começa com " $b$ ". Millôr simplesmente não leva em conta a aliteração, uma vez que em português o palavrão começaria com " $\mathrm{p}$ ". A brincadeira intencional de Shaw desaparece e a tradução perde em sentido e comicidade.

Já no Ato III, Eliza fala o palavrão com todas as letras e há toda uma discussão entre os personagens sobre a maneira de falar da florista. A tradução deste palavrão, "bloody", não ficou muito boa, pois a palavra era bastante forte e vulgar na Inglaterra, enquanto no português acabou ficando "normal":

“Liza: (...) Walk! Not bloody likely. (...) I am going in a taxi. $(\ldots)^{\prime \prime}($ p. 78)

“ Liza: (...) Pelo parque? A pé? (...) Que diabo, estou de táxi. $(\ldots)^{\prime \prime}($ p. 64)

“Clara: Such bloody nonsense!” (p. 79)

“Clara: Uma tolice disgranida!" (p. 65)

Observe que na fala de Eliza, Millôr traduz "bloody" como "que diabo", e na fala de Clara a mesma expressão torna-se o adjetivo "disgranida", nada comparado com a carga de significado que o palavrão tem na língua original.

Há muitos outros exemplos interessantes e que devem ser estudados mais profundamente. Mas o pouco que vimos demonstra o quanto Millôr Fernandes trabalhou para fazer uma tradução bem próxima da obra original. 
Priscila Fernanda Furlanetto. Análise descritiva da tradução de Millôr Fernandes...

\section{Conclusão}

Ao analisar a tradução de Millôr Fernandes, fica evidente que o autor-tradutor acabou fazendo bastante uso de toda sua habilidade de escritor em sua tradução, pois tentou transpor o dialeto cockney de forma criativa para o português, inventando um "coquinei". É possível observar, todavia, que tal invenção não fugiu muito do que consideramos o linguajar caipira no Brasil.

Todas as expressões e todas as cenas cômicas foram transpostas de forma bastante engraçada e natural para o português, muito embora algumas expressões tenham se desatualizado e, hoje poucos ainda sabem o que elas um dia quiseram dizer. Infelizmente, esse é um eterno risco, pois expressões idiomáticas estão em constante mudança, assim como as culturas e línguas que as produzem.

Millôr cometeu alguns desacertos, como pudemos notar, mas traduzir é sempre um jogo muito arriscado e é preciso muita determinação, muita coragem e, sobretudo, muito talento - qualidades que Millôr mostrou ter de sobra.

\section{Referências Bibliográficas}

ARROIO, Rosemary. Oficina de Tradução - A teoria na prática. São Paulo: Editora Ática, 1986.

BASSNETT-MCGUIRE, Susan. "Ways Trough the Labyrinth: Strategies and Methods for Translating Theatre Texts". In: HERMANS, T. (Org.). The Manipulation of Literature, Londres: Croom Helm, 1985.

BASSNETT-MCGUIRE, Susan. Translation Studies. Londres: Routledge, 1980.

CONTIERO, Lucinéia. Millôr Fernandes na Dramaturgia Brasileira. Assis: Unesp, 2001. 
FERNANDES, Millôr. “Sobre Tradução”. In: SHAKESPARE, William. A Megera Domada - tradução de Millôr Fernandes. Porto Alegre: L\&PM editora, 1979, p. 5-7.

FURLANETTO, Priscila F. Correspondência Eletrônica com Millôr [mensagem pessoal]. Mensagem recebida de <milloronline@uol.com.br> em 05 e 21 jan.2004.

MILTON, John. O Clube do Livro e a Tradução. Bauru: Edusc, 2002.

PAULILLO, Maria Célia. Millôr Fernandes. São Paulo:Abril Literatura Comentada, 1980.

ROBERTS, James L. Pygmalion Notes. Cliff'snotes. Nebraska, USA: Incorporated Lincoln, 1959.

REASKE, Christopher Russell. How to analyse drama. New York: Department of English Harvard University. Monarch Press, 1966.

RÓNAI, Paulo. Escola de Tradutores. Rio de Janeiro: Tecnoprint Gráfica S.A., 1981.

SHAW. G. B. Pygmalion- A romance in five acts- Definitive text. London: Penguin Books, 1957.

SHAW, G.B. Pigmaleão. Tradução de Millôr Fernandes. Rio de Janeiro: Documento datilografado pelo próprio tradutor, 1963.

SILVEIRA, Brenno. A Arte de Traduzir. São Paulo: Editora UNESP. Melhoramentos, 2004. 